\title{
QUEEN'S
UNIVERSITY
BELFAST
}

\section{A methodology for the rapid characterization of Mode II delamination fatigue threshold in FRP composites}

Pitarresi, G., Scalici, T., Dellaira, M., \& Catalanotti, G. (2019). A methodology for the rapid characterization of Mode II delamination fatigue threshold in FRP composites. Engineering Fracture Mechanics, [106629].

https://doi.org/10.1016/j.engfracmech.2019.106629

\section{Published in:}

Engineering Fracture Mechanics

\section{Document Version:}

Peer reviewed version

\section{Queen's University Belfast - Research Portal:}

Link to publication record in Queen's University Belfast Research Portal

\section{Publisher rights}

Copyright 2019 Elsevier

This manuscript is distributed under a Creative Commons Attribution-NonCommercial-NoDerivs License

(https://creativecommons.org/licenses/by-nc-nd/4.0/), which permits distribution and reproduction for non-commercial purposes, provided the author and source are cited.

\section{General rights}

Copyright for the publications made accessible via the Queen's University Belfast Research Portal is retained by the author(s) and / or other copyright owners and it is a condition of accessing these publications that users recognise and abide by the legal requirements associated with these rights.

Take down policy

The Research Portal is Queen's institutional repository that provides access to Queen's research output. Every effort has been made to ensure that content in the Research Portal does not infringe any person's rights, or applicable UK laws. If you discover content in the Research Portal that you believe breaches copyright or violates any law, please contact openaccess@qub.ac.uk. 


\title{
A methodology for the rapid characterization of Mode II delamination
}

\section{fatigue threshold in FRP composites}

\author{
Giuseppe Pitarresi $^{1 *}$, Tommaso Scalici ${ }^{2}$, Marco Dellaira ${ }^{1}$, Giuseppe Catalanotti ${ }^{3}$ \\ ${ }^{1}$ Dipartimento di Ingegneria - Università degli Studi di Palermo, Viale delle Scienze Ed. 8, 90128 Palermo, Italy \\ (giuseppe.pitarresi@unipa.it) \\ ${ }^{2}$ Advanced Composites Research Group (ACRG), School of Mechanical and Aerospace Engineering - Queen's \\ University Belfast, Belfast BT9 5AH, UK (t.scalici@qub.ac.uk) \\ ${ }^{3}$ Advanced Composites Research Group (ACRG), School of Mechanical and Aerospace Engineering - Queen's \\ University Belfast, Belfast BT9 5AH, UK (g.catalanotti@qub.ac.uk)
}




\begin{abstract}
A new methodology to measure the Mode II interlaminar fracture in fatigue for FRP composites is developed. The proposed methodology uses a Modified Transvers Crack Tensile (MTCT) specimen and is able to characterise the near threshold behaviour in a robust, easier and significantly faster way than standard procedures. Analytical formulae, able to link the crack growth rate to the load or strain amplitudes, were found and verified, and their importance was explained, in particular, for what concerns the characterisation of the near threshold behaviour. Experiments were performed both in load and strain control, while the delamination growth was monitored using different techniques including the Thermoelastic Stress Analysis (TSA). Experiments showed the reliability and effectiveness of the proposed procedure, and evidence its suitability and compatibility with current industrial material testing and qualification protocols with particular emphasis to industrial environment where a "no growth" design approach is employed.
\end{abstract}

Keywords: Fibre Reinforced Composites; Transverse Crack Tensile specimen; Mode II Fracture Toughness; Fatigue; Paris Law 


\section{Nomenclature}

\begin{tabular}{|c|c|}
\hline$a$ & delamination semi crack length \\
\hline$\Delta \mathrm{a}$ & crack length variation \\
\hline$\Delta \mathrm{N}$ & increment of the number of cycles \\
\hline$E$ & Young's modulus \\
\hline$G_{I I}$ & Strain Energy Release Rate under Mode II \\
\hline$G_{I I c}$ & Critical Strain Energy Release Rate under Mode II \\
\hline$G_{I I m a x} \mathrm{~S}$ & SERR at maximum load/strain/displacement in load/strain/displacement controlled fatigue cycles \\
\hline GIIth & Onset of delamination growth or threshold SERR \\
\hline$h$ & Thickness of the continuous plies skins \\
\hline$H$ & Total sample thickness \\
\hline$L_{g}$ & Extensometer gauge length \\
\hline$N$ & Number of fatigue cycles \\
\hline$P$ & Applied tensile load \\
\hline $\mathrm{R}$ & Stress ratio $\sigma_{\min } / \sigma_{\max }$ \\
\hline$\sigma$ & $\begin{array}{l}\text { Stress. If no sub-scripts are added, it indicates the nominal far field stress in the TCT and MTCT } \\
\text { samples }\end{array}$ \\
\hline I,II & sub-scripts indicating Mode I (opening tensile) and Mode II (in-plane shear). \\
\hline $1,2,3$ & sub-scripts indicating the material principal directions ( 3 , out of plane, $1-2$ in plane) \\
\hline CFRP C & Carbon Fibre Reinforce Plastic \\
\hline DCB & Double Cantilever Beam \\
\hline ENF & End-Notched Flexure specimen \\
\hline FRP & Fibre Reinforced Plastic \\
\hline GRP & Glass Reinforced Plastic \\
\hline IR & Infrared \\
\hline MTCT $\mathrm{N}$ & Modified Transverse Crack Tension specimen \\
\hline R-Curve & Material Resistance Curve \\
\hline SERR S & Strain Energy Release Rate, equivalent to $G_{I I}$ \\
\hline TCT & Transverse Crack Tension specimen \\
\hline TSA & Thermoelastic Stress Analysis \\
\hline UD & Unidirectional lamina/laminate \\
\hline
\end{tabular}




\section{Introduction}

Delamination is a common type of damage in Fiber Reinforced Polymer composite laminates which arises from poor manufacturing, cyclic stress, impact or anomalous loading (such as drop weight impact loading). Pure shear Mode II in particular is typical of several structural composite components loaded prevalently under in-plane shear loading. Some situations which favor Mode II delamination may include: low-velocity impact; the presence of ply-drops and splice joining in large composite assemblies [1,2]; interface delaminations from intra-laminar crack tunneling in fibre-metal laminates [3]; delamination propagation from holes in bolted joints, where the pressure of the bolts favors Mode II propagation [4].

Since composite transportation structures are usually required to withstand complex fatigue loading scenarios, a conservative damage tolerance methodology is often adopted by designers to avoid fatigue delamination growths up to critical levels, the so-called "No Growth" approach (see also [57]). This method is based on the knowledge of the fatigue threshold of the material in presence of a delamination, so that the stress field developed by in-service loads would never reach the conditions for further fatigue delamination growth. Furthermore, it has been observed that the most advanced and updated fatigue crack growth models for composites still lack the sufficient confidence and verification to be extended from characterization of laboratory test coupons onto real structures design [5]. In [8] it is observed how fatigue growth models for FRPs are often built upon data with high degrees of scattering, if compared to metals, and this is generally due to the variegate presence of damage mechanisms in FRPs. As a consequence, industry is constantly looking for reliable and realistic design limits, such as fatigue thresholds $G_{I I t}$.

The determination of the fatigue thresholds is usually obtained from the characterization of the subcritical crack growth domain in plots of $\mathrm{d} a / \mathrm{d} N$ versus $G_{\text {IImax }}$ on log-log scale [5]. Due its simple geometry and setup, the End Notched Flexure (ENF) is the most used and also the only standardized test coupon for the evaluation of the quasi-static fracture toughness $G_{I I c}$. This test coupon and the related data reduction are also the most popular choices for the analysis of fatigue behavior, including 
both the onset and growth stages [7]. Two approaches are generally proposed: one considering constant amplitude loading and one adopting constant displacement loading.

In constant amplitude loading, a lengthy but reliable approach to obtain $G_{\text {IIth }}$ consists of finding the $G_{\text {IImax }}$ value at which no crack growth is observed after $1,800,00$ cycles [9]. A more accelerated procedure to obtain $G_{I I t h}$ is by extrapolation, after fitting values of $G_{\text {IImax }}$ versus the number of cycles required to achieve a $1 \%$ or $5 \%$ compliance increase $[10,11]$. This so called G-N approach is derived from works of on Mode I DCB tests [12-14]. In order for the fitting to yield reliable extrapolations of $G_{\text {IIth }}$, values of $G_{\text {IImax }} / G_{c}$ as low as 0.2 are generally applied. Such low $G_{\text {IImax }}$ values generally require near $10^{5}$ cycles to determine a $1 \%$ compliance increase. Therefore the evaluation of $G_{I I t h}$ from the ENF is a lengthy and operator labor intensive procedure, which requires at least the following steps: initial quasi-static tests for the characterization of the compliance versus crack length calibration curve, setting of different values of $G_{\text {IImax }}$ and subsequent cycling up to at least $1 \%$ compliance increase, which generally requires several samples, each needing its own calibration and setting time. It is observed also that the previous procedure does not yield a natural continuous evolution of the subcritical crack growth curve, since curves from different $G_{\text {IImax }} / G_{c}$ do not overlap in the onset region [11]. Furthermore, values of $G_{I I t h}$ have been found to be rather sensitive to the kind of initial crack configuration used [11].

In constant displacement loading, the increase of crack length determines a continuous decrease of $G_{\text {IImax }}$ which will eventually lead to a natural delamination arrest. The value of $G_{I I t h}$ can then be extrapolated by implementing a G-N approach as mentioned earlier. This approach has been found effective for Mode I DCB tests [12], and is also suggested in ASTM D6115 [15]. With ENF samples a problem arise. As the delamination grows, it will gradually approach the sample mid-span, where the external load is applied. Here frictional effects and through-the-thickness compression loads increase significantly, and produce an early crack arrest which is not representative of the material $G_{I I t h}[7,9]$. Moreover, the amount of crack growth rate curve swept in a single test is generally small, and not sufficient to effectively characterize the sub-critical crack growth domain [7]. A way to 
overcome such limitation is performing tests on different samples and various constant cyclic displacement [16], but this remains oneorus in terms of time and material needed. In [7] it is proposed an automated procedure able to apply different cyclic displacement ranges on a single sample under the same fatigue cycling test. This is found to effectively extend the measured crack growth curve down to a $G_{I I m a x} / G_{c}$ severity of 0.1 with a consistent saving in time.

As outlined above, the reliable evaluation of onset $G_{I I t h}$ thresholds generally requires lengthy and costly experimental campaigns [2], with several preliminary tests, sample copuns and continuous intervention of an operator. This may represent a concern in the transportation industry (mainly aeronautic) that continuously strives to simplify and reduce the cost of material analysis and qualification procedures.

The present work proposes a methodology which is able to characterize the mode II fatigue delamination threshold region with a single test and a reduced number of cycles (generally under $10^{5}$ ). The presented approach employs a modified Transverse-Crack-Tension (MTCT) specimen, recently revisited by the authors [17]. The TCT specimen is a tensile sample where a number of internal plies were cut across the beam width, forming an embedded transverse notch. It was introduced and mainly developed in the late eighties/early nineties by [18-20]. In the MTCT version, artificial delaminations are also added across the transverse notch tips during the manufacture. When the MTCT is subject to tensile cyclic loading, pure mode II fatigue interlaminar delamination is favored and activated from the tips of the artificial delaminations [17,21].

One advantageous feature of the MTCT is that the SERR (Strain Energy Release Rate) is not dependent on the crack length, but rather on the square of the applied remote stress. This means that, under a load-control cyclic loading, the delamination growth is kept at a constant rate.

In the following, an analytical formulation to determine the crack growth rate, $\mathrm{d} a / \mathrm{d} N$, under load, displacement and strain control conditions is proposed and experimentally validated. Experiments showed that the proposed methodology provides an effective, reliable, and fast way to characterize the material fatigue Mode II crack onset and propagation. In some respects, the proposed 
implementation of the MTCT test under strain or displacement control conditions provides similar advantages to those described in other compliance methods such as DCB for Mode I and ENF for Mode II when applying displacement control $[7,16]$. At the same time, some drawbacks typical of ENF samples are overtaken, e.g.: it is not necessary to perform a compliance calibration, the sample loading severity is able to converge relatively rapidly to the threshold value and conventional external extensometers have proven to be high sensitivity and robust devices able to capture and sense actual growth rates near the arrest condition.

Experiments confirm the validity of the proposed methodology, emphasizing the ability to provide a full characterization of the threshold region. The work makes also use of IR thermography and Thermoelastic Stress Analysis to remotely monitor the sample fracture behavior, following methodologies developed in [21].

\section{Materials and Methods}

\section{$2.1 \quad$ Testing methodology}

The MTCT specimen is schematically represented in Figure 1. It consists of a tensile sample manufactured by stacking a number of unidirectional plies in which a number of internal layers, laying symmetrically across the mid plane, are cut transversally along the beam width, thus creating a central transverse notch. Tensile loading will activate four delamination fronts from the notch tips, which will be subject to a pure mode II condition after a certain delamination length threshold has been reached [17]. In order to promote a pure Mode II propagation at the delamination fronts, and better control the delaminations onset and growth, Scalici et al. [17] have found useful to introduce pre-crack delamination inserts across the notch tips, calling such change in the TCT preparation as modified-TCT specimen (or MTCT). 


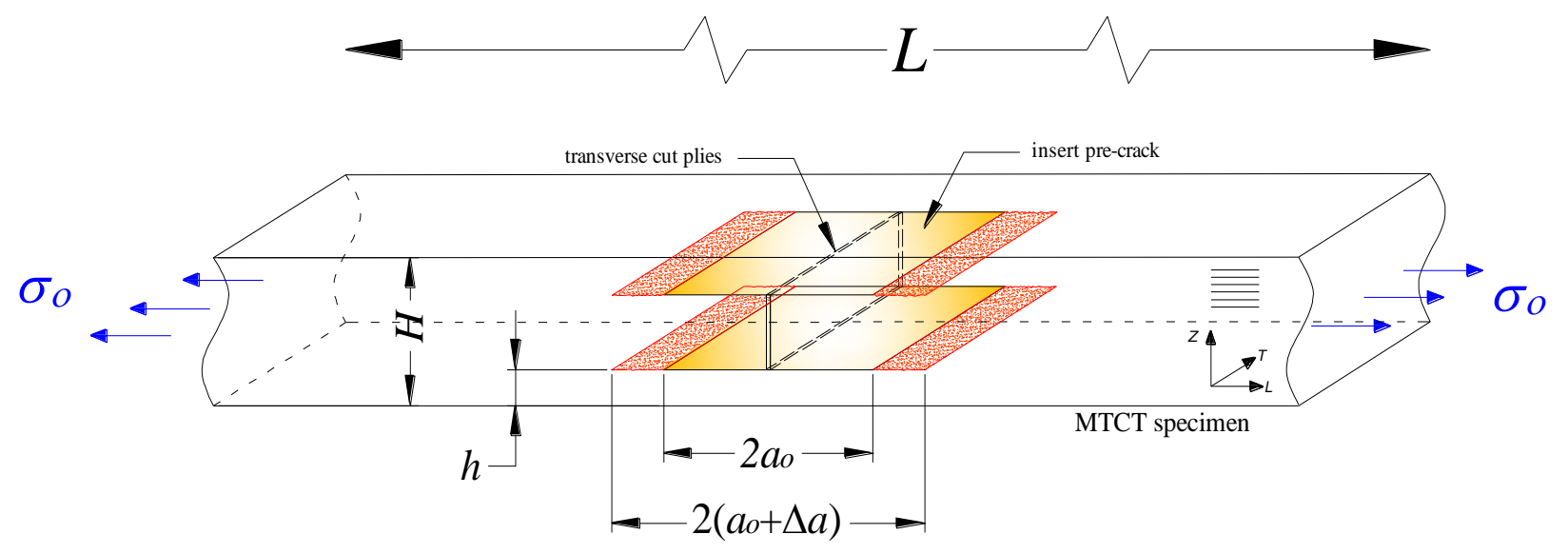

Figure 1: Sketch of a Modified TCT specimen

The formulation of the SERR, based on the evaluation of the specimen compliance from simple beam theory [22,23], for the MTCT can be written as:

$$
\begin{gathered}
G_{I I}=\sigma^{2} \frac{H}{4 E_{1}}\left(\frac{1-\eta}{\eta}\right) \text { with } \eta=\frac{2 \mathrm{~h}}{H} \\
G_{I I}=\frac{P^{2}}{4 B^{2} H E_{1}}\left(\frac{1-\eta}{\eta}\right) \text { with } \eta=\frac{2 \mathrm{~h}}{H}
\end{gathered}
$$

where $E_{l}$ is the Young's modulus in the fiber direction and the remote stress $\sigma$ can also be written as $P / B H$. According to [17], if the ratio $a / H$, with $a$ the initial pre-crack, is larger than a threshold value (which was calculated to be about 2.5 for specimens characterized by $\eta=0.5$ ), then Eq. 1 rules, and $G_{I I}$ is proportional to $\sigma^{2}$ and will not depend on $a$.

Equation 1 presents a number of features which bring some advantages for both monotonic (i.e. static) and fatigue fracture toughness characterization, which are highlighted in the next two sub-sections.

\subsection{Monotonic loading}

According to Eq. 1 a monotonic test in load control will gradually increase the driving force. Since there is no dependence on $a$, the portion of the crack driving force curve in the proximity of the Rcurve is a horizontal line. For a given load, therefore, the derivative to the crack driving force curve 
with respect the crack increment, $\Delta a$, is always null, while the derivative of the R-curve, at the same point, is positive in the rising part of the R-curve, attaining a null value only in the plateau. Hence the critical load will occur when the crack driving force curve is tangent to the plateau of the R-curve, and therefore the experimental determination of critical load allows to determine the steady-state value of the critical SERR (see [21,24] for a more in-depth discussion).

Some advantages that can be highlighted from the adoption of the MTCT specimen can be summarized as follows:

- $G_{I I}$ does not depend on the crack length $a$;

- Mode II fracture toughness can be measured with a testing setup as simple as a tensile test;

- The steady-state value of the fracture toughness is obtained. If this would have not been ensured, the fracture toughness measured would be lower than the steady-state value, because the tangent point would be in the rising part of the R-curve. This fact has a significant relevance since, generally, analytical and numerical strength analysis methods for composite structure require the steady state value for the definition of the softening law. The use of a lower value would provide a conservative estimation of the strength of the structure but would result in an oversizing of the structure with consequent increase in weight and cost;

- The specimen type and loading rig allow for an easy implementation of optical, non-contact, Experimental Stress Analysis, and NDT techniques (see e.g. [21] for the case of Thermoelastic Stress Analysis).

\subsection{Fatigue Loading: load control}

The TCT coupon has also been proposed and used for fatigue characterization [20,22,23,25-28].

The artificial pre-cracks in the MTCT do not modify the fatigue behavior, as fatigue cracks will grow from the pre-crack tips. An advantage over the TCT is that this last specimen may easily lead to unsymmetrical fatigue crack growth among the four expected delamination fronts, due to non- 
homogeneities in the transverse notch. For this reason the preparation of the transverse notch requires a special care in the TCT, that is instead not necessary in the MTCT [21].

The output of a Fatigue crack growth characterization is a Paris-like law, which correlates the average delamination rate $\mathrm{d} a / \mathrm{d} N$ with a parameter describing the fractured energy available. This last parameter is by some authors defined as the maximum SERR normalized by the critical SERR, i.e. $G_{I I m a x} / G_{I I c}$, where $G_{I I c}$ is obtained from monotonic tests.

Since $G_{I I}$ is not dependent on $a$ but only on $P$, the value of $G_{I I m a x}$, and consequently of $\Delta a / \Delta N$, would be constant for a given load amplitude (characterized by the peak load, $P_{\max }$, and the stress ratio, $R$ ), see Eq. 1b. This allows to obtain a point of the Paris' curve by growing the cracks for a sufficient distance, helping to measure $\Delta a$ with good accuracy. The evaluation of $\mathrm{d} a$ in ENF tests is for instance carried out under a continuous evolution of $G_{I I}$, which forces to consider small compliance variations (see e.g. the 2-point secant method, [11]), generating noisy data which require some further parsing and smoothing treatments.

In the literature, the nondestructive measurement of $\Delta a$ was implemented via three approaches:

- By means of visual inspections, usually performed on the sample thickness face;

- By means of contact and non-contact Experimental Strain Analysis techniques acting on both the sample thickness and width faces (see e.g. Ribeiro et al. [29] for the use of embedded optical fibres, and Pitarresi et al. [11,12] for the use of TSA);

- By means of extensometers, whose gauge length comprises the delaminated region (see Figure 2) [23].

The use of extensometers is in particular considered in this work. These are used to monitor the variation of the specimen compliance during crack extension, which can also be correlated to the actual delamination length and to its growth rate. In particular, considering the sketch in Figure 2a, the following derivation of the semi crack length $a$ as a function of the extensometer output $\varepsilon_{e x t}$ is illustrated. 

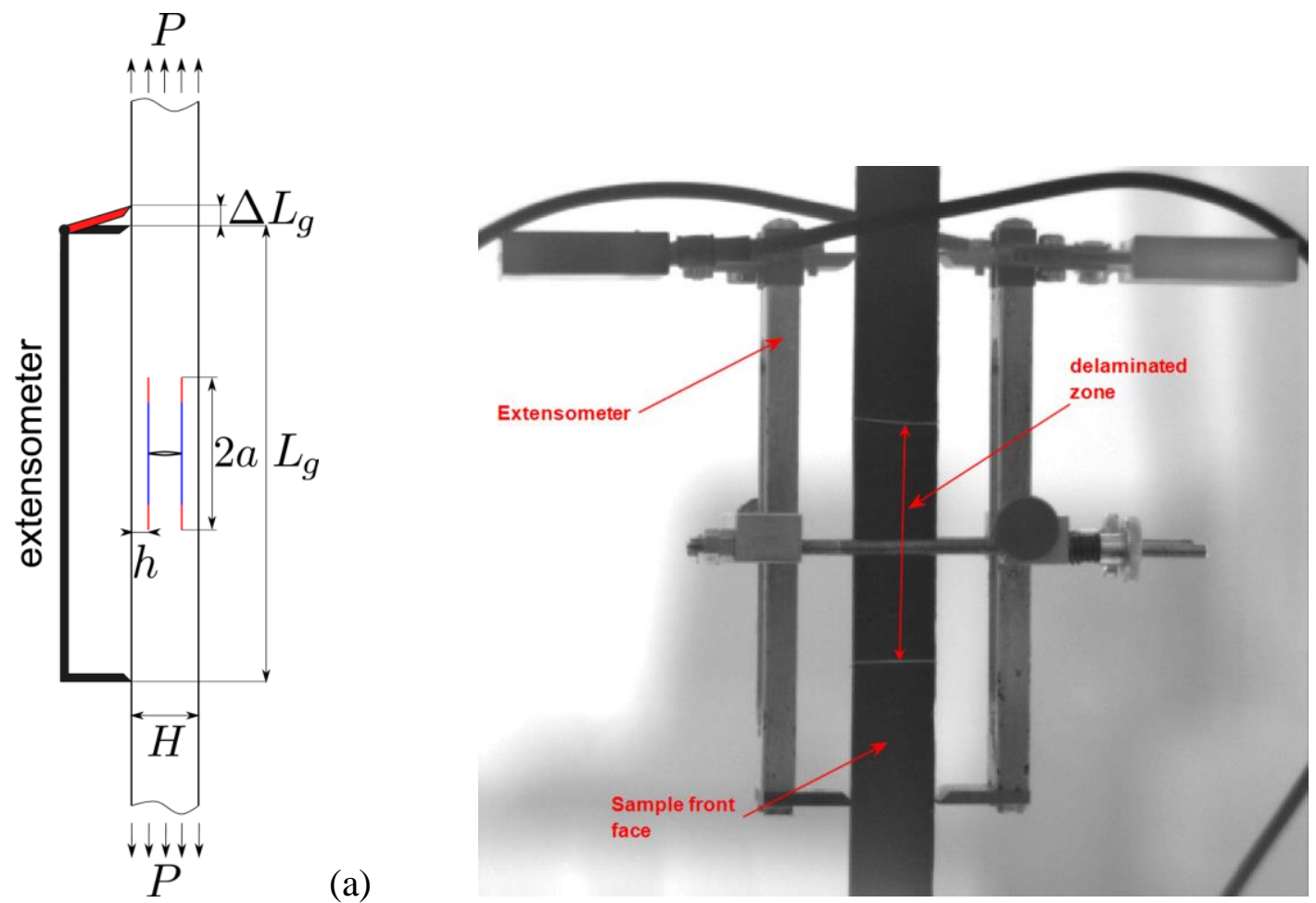

(b)

Figure 2: (a) Sketch of an MTCT sample instrumented with the extensometer; (b) image of the HBM-dd1 strain indicator assembled in an averaging double opposed clamp-on configuration.

The extensometer measures the load induced variation of its gauge length $L_{g}$, providing the deformation $\varepsilon_{e x t}=\left(\Delta L_{g}\right) L_{g}$ Such extension $\Delta L_{g}$ can be seen as the sum of the extensions of the delaminated and non-delaminated (i.e. sound) portions of sample included inside the gauge length. These can be respectively indicated as $\Delta_{d}$ and $\Delta_{s}$, and amount to:

$$
\Delta_{s}=\varepsilon_{s} \cdot\left(L_{g}-2 a\right)=\frac{P}{B H} \frac{1}{E_{1}} \cdot\left(L_{g}-2 a\right) ; \quad \Delta_{d}=\varepsilon_{d} \cdot(2 a)=\frac{P}{B H \eta} \frac{1}{E_{1}} \cdot(2 a)
$$

Hence, the extensometer measured deformation is given by:

$$
\varepsilon_{\text {ext }}=\frac{\Delta_{s}+\Delta_{d}}{L_{g}}=\frac{P}{B H E_{1}} \frac{1}{L_{g}}\left[2 a\left(\frac{1-\eta}{\eta}\right)+L_{g}\right]
$$

and the delamination length is obtained as a function of $\varepsilon_{e x t}$, as:

$$
2 a=L_{g}\left(\frac{\eta}{1-\eta}\right)\left(\frac{B H}{P} E_{1} \varepsilon_{e x t}-1\right)=L_{g}\left(\frac{\eta}{1-\eta}\right)\left(\frac{E_{1}}{E_{e x t}}-1\right) \text { where } E_{e x t}=\frac{\sigma}{\varepsilon_{e x t}}=\frac{P}{B H} \frac{1}{\varepsilon_{e x t}}
$$


If the test is performed in fatigue with a constant load amplitude, Eq. 4 can be differentiated with respect to $N$, yielding the crack growth rate as:

$$
\frac{\mathrm{d} a}{\mathrm{~d} N}=\frac{E_{1} B H L_{g}}{2 P^{\prime}}\left(\frac{\eta}{1-\eta}\right) \frac{\mathrm{d} \varepsilon_{e x t}^{\prime}}{\mathrm{d} N}
$$

where $\varepsilon_{\text {ext }}^{\prime}$ is the strain measured by the extensometer at the load $P^{\prime}=P_{\max }$. It could be convenient to setup the universal testing machine to sample the values of $\varepsilon_{\text {ext }}$ at each load peak, so that the slope of the plot of these values versus the number of cycles will provide the derivative in Eq. 5, and then the crack growth rate [28].

\subsection{Fatigue loading: strain control}

The present work extends the application of the MTCT specimen to the case of displacement or strain controlled fatigue loading. When a MTCT sample is cyclically loaded under generic displacement control, the compliance of the sample is progressively increased by the growing of delaminations. In order to maintain the same displacement amplitude, the applied peak-to-peak load and the SERR will also gradually reduce. This evolving scenario will eventually bring to the natural conditions of crack arrest. When such conditions are achieved, the SERR corresponding to the peak-to-peak load at arrest will represent the fatigue threshold of the material.

In order to monitor and measure the compliance reduction, it is more practical to apply a strain control fatigue loading, where the testing machine is controlled by the signal from the extensometer, such that fatigue loading is applied under the condition of a constant peak-to-peak strain, $\varepsilon_{\text {ext }}^{\max }$. If the extensometer gauge length is longer than the initial delamination of the MTCT, and the strain amplitude is opportunely chosen, then the crack growth will arrest when the delamination is still confined within the extensometer knives. Under strain control, the applied load will be a function of the number of cycles, and in particular it is expected that the load $P$ will gradually reduce with the growing of the delamination, asymptotically aiming at a constant value which is also the delamination 
threshold value. In light of this, in Eq. 4 the load is a function of $N$, and $\varepsilon_{\text {ext }}$ should be handled as a constant value, so that the crack growth rate in strain control now becomes:

$\frac{\mathrm{d} a}{\mathrm{~d} N}=-\frac{E_{1} B H L_{g}}{2}\left(\frac{\eta}{1-\eta}\right) \frac{\mathrm{d} P^{\prime}(N) / \mathrm{d} N}{P^{\prime}(N)} \varepsilon_{e x t}^{\prime}$

In Eq. $6, P^{\prime}$ refers to the maximum load at each cycle while $\varepsilon_{\text {ext }}^{\prime}=\varepsilon_{\text {ext }}^{\max }$ is the maximum extensometer strain, which now is a constant. In strain control loading, $P^{\prime}$ is a function of the number of cycles $N$, which brings in the term of the derivative $\mathrm{d} P^{\prime} / \mathrm{d} N$. Since the load $P^{\prime}$ will decrease with the growing of the crack, its derivative in $N$ is negative, and then the sign of $\mathrm{d} a / \mathrm{d} N$ from Eq. 6 is still positive. Furthermore, $P^{\prime}$ will tend to a constant threshold value, which means that the derivative $\mathrm{d} P^{\prime} / \mathrm{d} N$ will tend to zero, bringing the value of crack growth rate to zero, i.e. to crack arrest.

It is observed that Eq. (6) provides an effective automatic way for continuously measuring $\mathrm{d} a / \mathrm{d} N$ independently from the operator and the application of external visual devices. It relies on the use of standard extensometers. Alternative relationships could be obtained for operating in displacement control, thus avoiding the use of extensometers. In this case, a preliminary compliance calibration would be necessary to include the influence of the gripping zone in Eq. (2), which now will correlate the total sample displacement with the delaminations lengths $2 a$. If the value of $G_{I I t h}$ is the only characterization needed, and the crack growth curve is not required, then the evaluation of $\mathrm{d} a / \mathrm{d} N$ from Eq. (6), or other similar compliance relationships, can be ignored. In this case the evolution of the maximum load will be the only parameter acquired, and the extensometer strain, or the cross-head displacement, which are sensitive to the presence of crack growth regardless of the underlying analytical relationship, will drive the test up to the crack arrest condition, and then will maintain this status. In particular, the extensometer, which is able to catch the average growing behavior of the four fronts, will give a constant signal only when there is no more growth in all single crack fronts. Therefore, in the evaluation of the fatigue threshold, the extensometer can be used only just as a qualitative sensor signal dictating the stop of crack growth. 


\subsection{Materials}

The MTCT samples tested in this work were obtained from a $300 \times 300 \mathrm{~mm}^{2}$ GRP panel that was manufactured in-house by resin infusion. The impregnated laminate was consolidated under vacuum bag pressure and cured at room temperature for $24 \mathrm{~h}$, under vacuum pressure. Room temperature curing was also followed by a thermal post-cure at $60{ }^{\circ} \mathrm{C}$ for $12 \mathrm{~h}$.

The raw materials used consist of:

- a UD glass fabric, with areal weight $300 \mathrm{~g} / \mathrm{m}^{2}$, made of yarns interwoven with low-tex weft ties, which introduce a slight crimping;

- $\quad$ a MATES SX8 EVO epoxy resin coupled with its own medium speed hardener (i.e., modified cycloaliphatic polyamine), supplied by Mates Italiana srl, suitable for room temperature curing (mixing ratio: 100/30).

The panel lay-up is $[0]_{12}$ and the number of central cut plies was 6 (i.e. $\eta=0.5$ ). The pre-crack delaminations were introduced during the panel assembly, by laying two stripes of a FEP release film, $13 \mu \mathrm{m}$ thick, across the central cut, between the continuous and cut plies interface, dimensioned to provide a pre-crack nominal length $2 a=30 \mathrm{~mm}$.

Twelve nominally identical tensile beam samples were cut, with the beam axis parallel to the fibres direction. Samples have nominal planar dimensions of $250 \times 15 \mathrm{~mm}^{2}$ and a measured thickness of $5.72 \pm 0.13 \mathrm{~mm}$. The average fibres volume fraction, calculated by weighing each sample and neglecting voids, amounts to about $54 \%$.

\subsection{Experimental plan and mechanical setup}

Table 1 summarises the plan of experiments and describes the type of tests carried out on each of the 12 samples. Table 2 and Table 3 provide further details about the parameters set in fatigue tests under load and strain control. 
Table 1: Plan of experiments: test type and test parameters adopted for each MTCT sample.

\begin{tabular}{|c|c|c|c|}
\hline$\underset{\text { ID }}{\text { Sample }}$ & Type of test & Testing parameters & Purpose \\
\hline 1 & $\begin{array}{l}\text { Monotonic up to } \\
\text { failure }\end{array}$ & Load control $5 \mathrm{kN} / \mathrm{min}$ & $\begin{array}{l}\text { Proof loading and evaluation of } \\
E_{l} \text { and } G_{I I c}\end{array}$ \\
\hline 2,3 & $\begin{array}{l}\text { Monotonic up to } \\
\text { failure }\end{array}$ & Displacement control $1 \mathrm{~mm} / \mathrm{min}$ & $\begin{array}{l}\text { Proof loading and evaluation of } \\
E_{l} \text { and } G_{I I c}\end{array}$ \\
\hline 4 & $\begin{array}{l}\text { Fatigue in load } \\
\text { control }\end{array}$ & $5 \mathrm{~Hz}$; load range up to $1 \div 13 \mathrm{kN}$ & $\begin{array}{l}\text { Proof tests to evaluate the ability } \\
\text { to control crack growth at } \\
\text { different load ranges }\end{array}$ \\
\hline $5,6,7,8$ & $\begin{array}{l}\text { Fatigue in load } \\
\text { control }\end{array}$ & $\begin{array}{l}\text { Sinusoidal loading with } R=0.1 \\
\text { and max load } P \text { calculated such } \\
\text { to obtain ratios of } \\
G_{\text {IImax }} / G_{I I C}=0.2 ; 0.24 ; 0.3 ; 0.4 ; \\
0.5 \text {. See table } 2\end{array}$ & $\begin{array}{l}\text { Obtained } 5 \text { point in the linear } \\
\text { portion of the Paris curve } \mathrm{d} a / \mathrm{d} N \\
\text { versus } G_{\text {IImax }} / G_{I I c}\end{array}$ \\
\hline 9 & $\begin{array}{l}\text { Fatigue in } \\
\text { displacement } \\
\text { control }\end{array}$ & $\begin{array}{l}\text { Sinusoidal displacement wave } \\
\text { between } 0.085 \div 0.85 \mathrm{~mm} \text { carried } \\
\text { out for } 10^{5} \text { cycles. }\end{array}$ & $\begin{array}{l}\text { Proof of gradual delamination } \\
\text { arrest and compliance increase in } \\
\text { a constant displacement amplitude } \\
\text { fatigue test }\end{array}$ \\
\hline $10,11,12$ & $\begin{array}{l}\text { Fatigue in strain } \\
\text { control }\end{array}$ & See Table 3 & $\begin{array}{l}\text { To obtain the Paris curve near the } \\
\text { threshold point. }\end{array}$ \\
\hline
\end{tabular}

Table 2: Fatigue tests under load control with $R=0.1$ and load frequency $5 \mathrm{~Hz}$.

\begin{tabular}{|c|c|c|c|c|}
\hline Sample ID & 5 & 6 & 7 & 8 \\
\hline Number total cycles & 16943 & $\begin{array}{l}13999 \\
21080\end{array}$ & 6322 & 2400 \\
\hline$P_{\max }[\mathrm{kN}]$ & 10 & $\begin{array}{l}9.1 \\
11.5\end{array}$ & 12.86 & 14.38 \\
\hline$G_{I I m a x} / G_{I I C}$ & 0.24 & $\begin{array}{l}0.2 \\
0.3\end{array}$ & 0.4 & 0.5 \\
\hline
\end{tabular}

Table 3: Fatigue tests under strain control with $R=0.1$ and load frequency $5 \mathrm{~Hz}$.

\begin{tabular}{cccc}
\hline Sample ID & 10 & 11 & 12 \\
\hline Number total cycles & 72000 & 140000 & 140000 \\
$\varepsilon_{\max }$ & 4300 & 4300 & 3800 \\
\hline
\end{tabular}

All tests were run on a MTS 810 universal testing machine (100 kN load cell capacity), remotely controlled by a MTS FlexTest SE digital controller, equipped with MTS 647 hydraulic grips. The extensometer used for the determination of $E_{1}$ and for the strain-control feedback is a HBM dd1 strain 
indicator, assembled in an averaging double opposed clamp-on configuration (see Figure $2 \mathrm{~b}$ ). The extensometer is fully conditioned by the MTS digital controller, so that its signal is sampled synchronously with the other machine transducers and is suitable for closed-loop control. A preliminary optimization of the PID controller parameters was performed, which allowed to adjust the extensometer signal to meet perfectly the dynamic requirements of the applied fatigue loading cycles.

\subsection{Thermoelastic stress analysis (TSA)}

An IR camera, FLIR x6540sc, was used during both monotonic and fatigue tests. A full account of the advantages of IR Thermography, as an effective tool to monitor damage through thermograms acquired in a non-contact and full-field way, is given in $[11,12]$. Here it is quickly recalled that thermograms sampled during monotonic tests allow to identify the first load at which delamination damage first occurs, so that this load can be used as the critical value for the evaluation of $G_{\text {IIC. }}$ Regarding fatigue tests, the sampled thermograms are post-processed in the frequency domain with a lock-in filter [21,30], thus obtaining the thermoelastic signal. This, in particular, is correlated to the stress field, and allows to identify the evolution of the delamination by considering the special thermoelastic signatures activated by the cracked zones.

The experimental evaluation of $\mathrm{d} a / \mathrm{d} N$ during fatigue loading in load control was carried out in three different ways:

- Via Visual Inspection (VIS): this consisted in measuring the trace of the delamination on the sample thickness, by means of a zoom lens, at the end of the cyclic loading. The average of the four delamination propagations was then divided by the total number of cycles applied, to obtain a value of $\mathrm{d} a / \mathrm{d} N$;

- $\quad$ Via the Thermoelastic signal (TSA): the sample thermoelastic signal from both the thickness and width faces was constantly monitored during the application of cyclic loading. The propagation of the delamination fronts was then measured from the thermoelastic maps as 
described in $[11,12]$. The crack growth rate was derived from the linear regression of the measured crack growths versus the number of cycles;

- $\quad$ Via the extensometer signal (EXT): The measured maximum strain per each cycle is measured and plotted versus the number of cycles. A linear regression of such points provides the term $\mathrm{d} \varepsilon^{\prime}{ }^{\prime} x t / \mathrm{d} N$, which yields the crack growth rate $\mathrm{d} a / \mathrm{d} N$ through $E q .5$.

\section{Results and Discussion}

\subsection{Monotonic Characterization}

All twelve samples were preliminary loaded monotonically up to $10 \mathrm{kN}$ and then unloaded. This initial monotonic loading was applied in order to brake the resin pocket that is present in the transverse crack, and thus activate the full Mode II shifting between the continuous and discontinues plies. The load at which the resin pocket fractured was around $5 \mathrm{kN}$ for all samples [17]. Such preliminary monotonic loadings on all samples allowed also to evaluate the Young's Modulus $E_{l}$, and ascertain that all samples have similar stiffness responses. The Modulus $E_{1}$ was obtained by using $E q .4$, taking the values of $\varepsilon_{\text {ext }}$ from the extensometer and considering the initial delamination length $2 a=30 \mathrm{~mm}$. The obtained value, averaged over all 12 samples, is $E_{l}=37.7 \pm 0.8 \mathrm{GPa}$.

Figure 3 shows the monotonic load-displacement curves up to complete failure, measured from samples $1,2,3$. The failure behavior was similar in both load (sample 1) and displacement control (samples 2,3). The IR camera allowed to register the first critical load at which the delaminations started to propagate. In fact, the onset and progression of delamination after any arrest are always accompanied by a sudden local temperature increase, that is most likely due to a quick change in the stress level generating an intense thermoelastic temperature change that is rapidly diffused away in the case of quasi-static loading (see also [21] for a more in-depth description of such behavior). It is here interesting to underline that such instant is not detectable from the features of the loaddisplacement curves. In general, all samples showed an initial stable crack propagation, of the kind 
of a stick-slip behavior. This is probably due to the inhomogeneity of the material, i.e. the intrinsic crimping of the yarns and the presence of transverse weft ties.

In this work the assumed critical load was that occurring at the first indication of unstable crack growth, and this is detected by the IR camera. Such value is $P_{c}=20.3 \pm 0.7 \mathrm{kN}$, and the corresponding critical SERR was $G_{I I c}=2.1 \pm 0.1 \mathrm{~N} / \mathrm{mm}$. The rise of the load above the critical value indicates that the material exhibits a growing evolution of the R-Curve, which is due to the highly non-homogeneous material along the delamination plane.

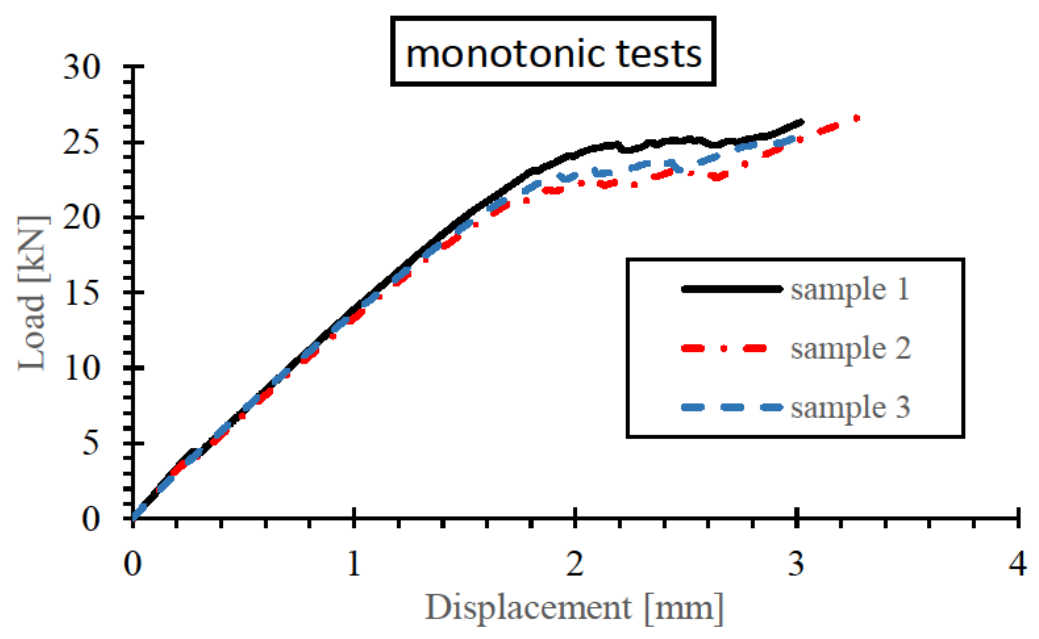

Figure 3: Plots of the Load-Displacement curves measured from monotonic tests up to failure on MTCT samples.

\subsection{Fatigue characterization: load control}

Fatigue testing under load control represents the standard procedure, implemented in the literature, for TCT and MTCT samples. As mentioned earlier, the value of $G_{I I}$ does not depend on the delamination length, but only on the applied load $P$, through Eq. 2. In this way, a sample can be subject to constant amplitude sinusoidal loading. Such fatigue loading is carried out for a sufficient number of cycles, during which the crack fronts are grown enough to allow evaluating a reliable crack growth rate $\mathrm{d} a / \mathrm{d} N$. The number of cycles required depends basically on the measuring technique and on the level of homogeneity of the material. Optical or IR techniques would increase their accuracy if the crack growth to be measured increases. If the extensometer is used, then $\mathrm{d} a / \mathrm{d} N$ can be obtained 
from the linear regression of max deformation versus the number of cycles. Again a higher number of cycles would improve the accuracy of the linear regression (see also Figure 5).

Figure 4 shows the obtained Paris' law from correlating, in a bi-logarithm plane, the measured values of $\mathrm{d} a / \mathrm{d} N$ versus $G_{\text {IImax }} / G_{\text {IIC }}$ on four samples (see Table 2).

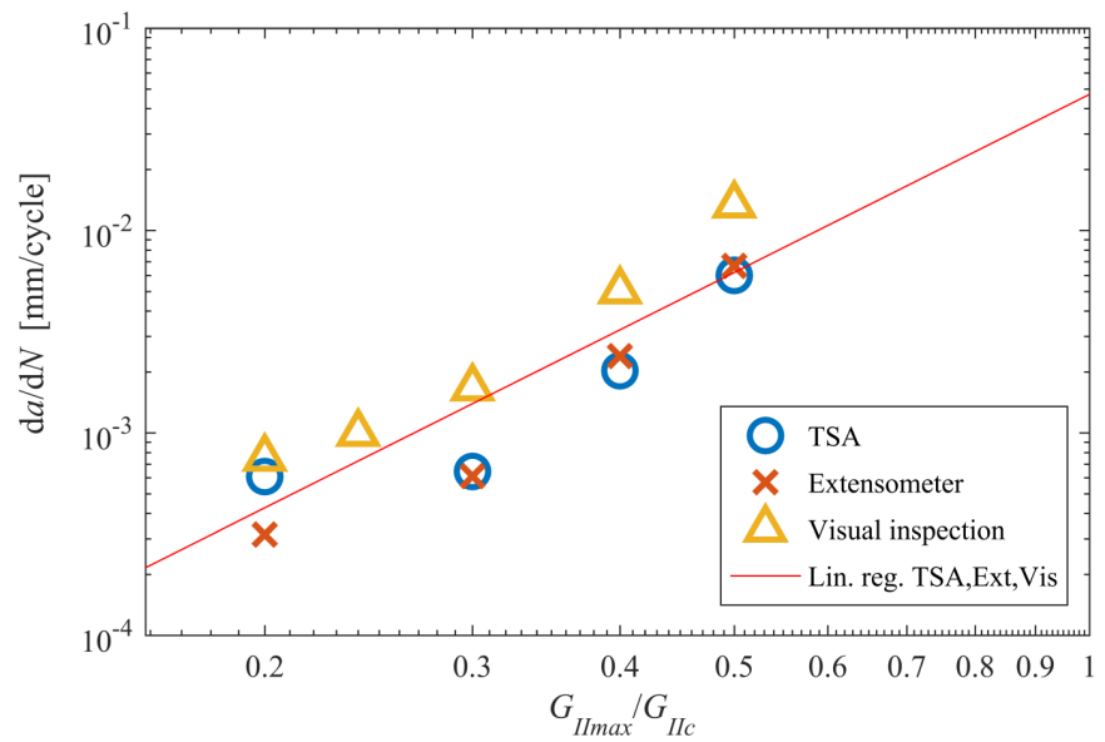

Figure 4: Paris law evaluation of the fatigue loading behaviour under load control.

From Figure 4 it is seen that there is a general good agreement between the EXT and TSA methods to determine the crack growth rate, while some differences are observed with the values from the VIS method. It has to be reported that the VIS method was applied on surfaces whose finish is affected by imprints left by the band saw used to slice the samples, and this was not ideal to help to distinguish the delamination traces from other sample scratches and non-homogeneities. Furthermore the VIS measurements were all performed only at the end of cycling, while the EXT and TSA methods monitored the cracks growths more constantly throughout cycling, deriving $\mathrm{d} a / \mathrm{d} N$ with a linear regression operation. An example of such interpolation and the evaluation of the crack growth with the EXT method is provided in Figure 5, where the black solid curve is referred to the experimental results while the red dotted one is a linear fitting curve. Similar trends can also be found in [21]. In particular the plot in Figure 5 follows a generally linear trend, with some local fluctuations. These fluctuations are introduced by the inhomogeneity of the material (the transverse weft ties in particular 
are believed to periodically slow or accelerate crack growth). To get a good average estimation of the strain rate to use in Eq. (5), and then to calculate the average crack growth rate, the sample must be tested for a rather wide number of cycles, and a rather extended crack growth, to reduce the influence of fluctuations. The authors believe that a more homogeneous composite, such as a pre-preg, should exhibit a more regular trend, requiring far less cycles to estimate a good average crack growth rate.

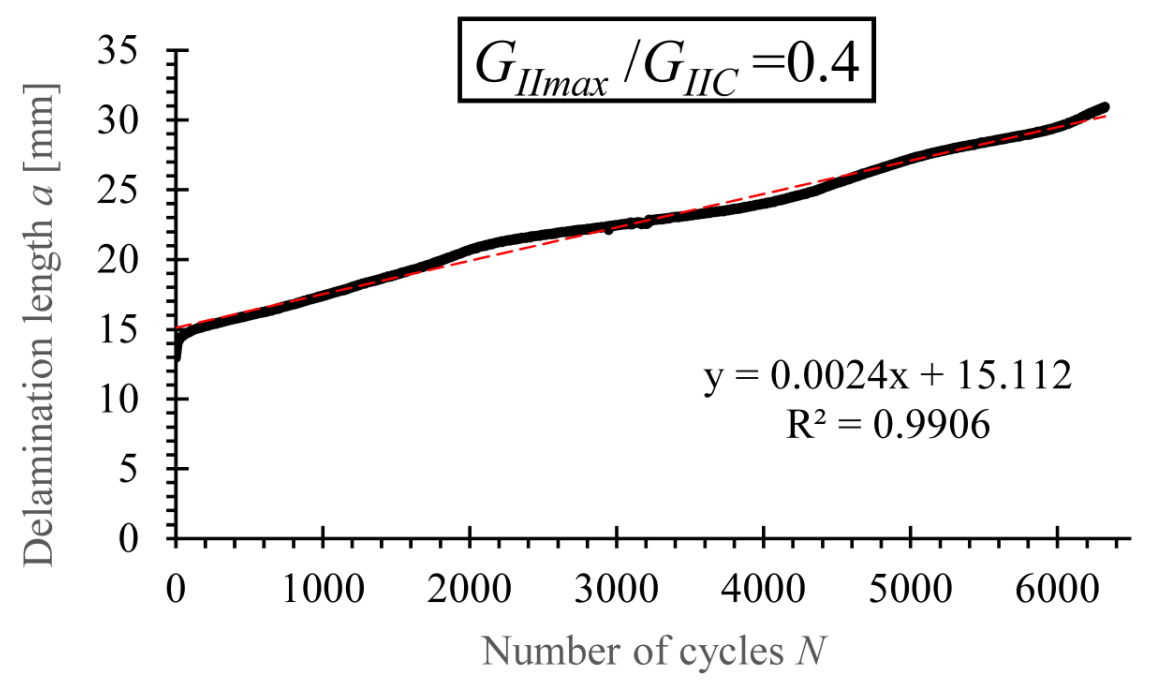

Figure 5: Example of average delamination growth as predicted with the EXT method.

\subsection{Fatigue characterization: strain control}

A preliminary proof test was carried out by setting the testing machine in displacement control, with sinusoidal cycles between 0.085 and $0.85 \mathrm{~mm}(R=0.1$, Frequency $5 \mathrm{~Hz})$. The load applied with a delamination $2 a=30 \mathrm{~mm}$ and a maximum displacement of 0.85 corresponds to about $12.5 \mathrm{kN}$, i.e. a value of $G_{\text {IImax }} / G_{\text {IIc }}=0.38$ and a maximum strain of $6140 \mu \mathrm{m} / \mathrm{m}$. Figure 6 a shows the evolution of the load at maximum displacement over 100000 cycles. During this cycling interval the delaminations average growth was about $70 \mathrm{~mm}$, and the increased compliance explains the reduction of the load. Another interesting and expected feature is the gradual reduction of the load drop rate. Indeed, as the compliance of the sample increases, the load reduction decreases the driving force $G_{I I}$ and the crack will eventually achieve the conditions of a natural arrest. At this point the load will remain constant. 
So it can be predicted that the threshold load behaves as a horizontal asymptote of the curve in Figure 6a.

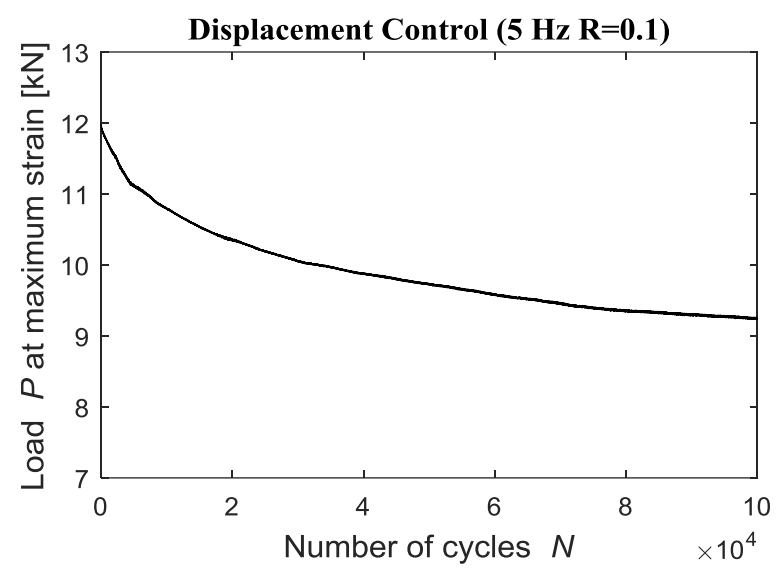

(a)

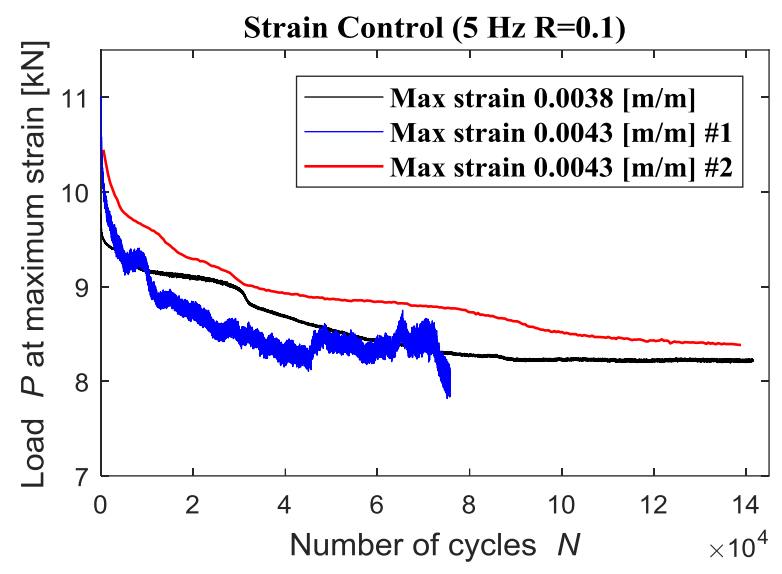

(b)

Figure 6: (a) Evolution of the load at maximum displacement during a fatigue test in displacement control; (b) evolution of the load at maximum strain in fatigue tests run in strain control.

Tests run in displacement control would be easier to implement since the extensometer is not strictly needed (the crack growth rate can be measured with a TSA or VIS method). It is though difficult to predict when the plateau in the load $P$ will be achieved. If the initial displacement amplitude gives rise to high values of $G_{I I m a x} / G_{I I c}$, then it could happen that the crack will be growing a long distance and a high number of cycles would be needed, before the threshold is reached, or the sample achieves final failure before reaching the propagation threshold.

By running tests in strain control, Eq. 6 can be applied. This relationship can be seen as a potential analytical expression of the whole Paris' curve, since it correlates $\mathrm{d} a / \mathrm{d} N$ to $P$ which is correlated to $G_{I I}$ (see Eq. 2). If the values of $P$ and $\mathrm{d} P / \mathrm{d} N$ are acquired experimentally from the testing machine, then the value of $\mathrm{d} a / \mathrm{d} N$ can be readily computed in both the linear and the threshold regions. Two sinusoidal strain cycles were applied: $380-3800 \mu \mathrm{m} / \mathrm{m}(R=0.1$, fr. $5 \mathrm{~Hz})$ and $430-4300 \mu \mathrm{m} / \mathrm{m}$ $(R=0.1$, Fr. $5 \mathrm{~Hz})$. The load corresponding to the maximum strain at the first cycle was previously calculated resulting in $6.8 \mathrm{kN}\left(G_{\text {IImax }} / G_{I I C}=0.092\right)$ with a delamination length of $100 \mathrm{~mm}$, while the second cycle foresees a load at maximum strain of about $7 \mathrm{kN}\left(G_{\text {IImax }} / G_{I I c}=0.118\right)$ with $2 a=100 \mathrm{~mm}$. 
The reason of considering $2 a=100 \mathrm{~mm}$ is that this is also the gauge length of the used extensometer. The extensometer is no longer able to detect further compliance increases if the delaminations overcomes the extensometer gauge length. Therefore, the rationale behind the choice of the above strain cycles is to set a very low value of $G_{I I m a x} / G_{I I c}$ at the gauge length, so that it is very likely that the delaminations will reach their natural arrest before their length overcomes the extensometer gauge length.

Figure $6 \mathrm{~b}$ reports the evolution of the load at maximum strain with fatigue cycles. Each curve is obtained from a different sample. It is first of all observed that the cycle $430-4300 \mu \mathrm{m} / \mathrm{m}$ was repeated twice. At the first run, the measured load signal was rather noisy. This was probably due to a nonideal setup of the extensometer. For this reason, the first run at 430-4300 $\mu \mathrm{m} / \mathrm{m}$ was stopped earlier, after about 70000 cycles. After increasing the clamp pressure and checking the tightening of the bolts holding the extensometer knives, the second run at $430-4300 \mu \mathrm{m} / \mathrm{m}$ showed a far smaller noise and a smoother curve, and the test was kept running up to 140000 cycles.

In order to obtain an analytical formulation of the Paris curve, all curves in Figure $6 \mathrm{~b}$ were interpolated with an exponential fitting model, of the type:

$$
P(N)=a e^{b N}+c e^{d N}
$$

where coefficients $a, b, c, d$ were calculated with a $95 \%$ confidence bound.

The analytical representation of $P(N)$ and its derivative $\mathrm{d} P / \mathrm{d} N$ are then replaced in $E q .6$ to evaluate $\mathrm{d} a / \mathrm{d} N$ and in Eq. 2 to evaluate $G_{I I}$. The resulting curves of $\mathrm{d} a / \mathrm{d} N$ versus $G_{I I m a x} / G_{I I c}$ are reported in Figure 7.

As shown in Figure 7, the above procedure yields smooth curves representing the threshold region of the Paris' law. It is in particular appreciated how all three curves have a well-marked regular knee, deviating the trend from linearity to a near perpendicular orientation, supposedly pointing to the threshold value. In the present work this threshold value is about $\left(G_{\text {IImax }} / G_{\text {IIc }}\right)_{t h}=0.17$. The curves 
relative to the $430-4300 \mu \mathrm{m} / \mathrm{m}$ strain cycle also show a very good fitting with the linear region of the Paris' law.

Some final considerations are made in order to validate the findings of the present work with those available in the literature. At this regard, it is observed that making quantitative comparisons is not easy since delamination toughness properties for GFRPs may differs substantially because of the constituents, fabric assembly and/or manufacturing process. When compared with similar experimental setups, the Paris linear domain of the sample tested in this work and in [21] compare reasonably well with the behavior of another GFRP tested with the TCT sample by Allegri et al [23]. If considering a different experimental setup, namely the ENF, very few data exist for glass fibre reinforced epoxy composites. Experiments conducted by Murri and Martin [31] report tests conducted on S2/SP250 material system. Depending on how the insert was made, threshold values for the mode II interlaminar fracture toughness were reported in the range $0.19-0.42 \mathrm{~N} / \mathrm{mm}$, and in particular with an average value of $0.31 \mathrm{~N} / \mathrm{mm}$ and a standard deviation of $0.08 \mathrm{~N} / \mathrm{mm}$. The value found in our investigation is $0.357 \mathrm{~N} / \mathrm{mm}$ that is in the range previously found by Murri and Martin.

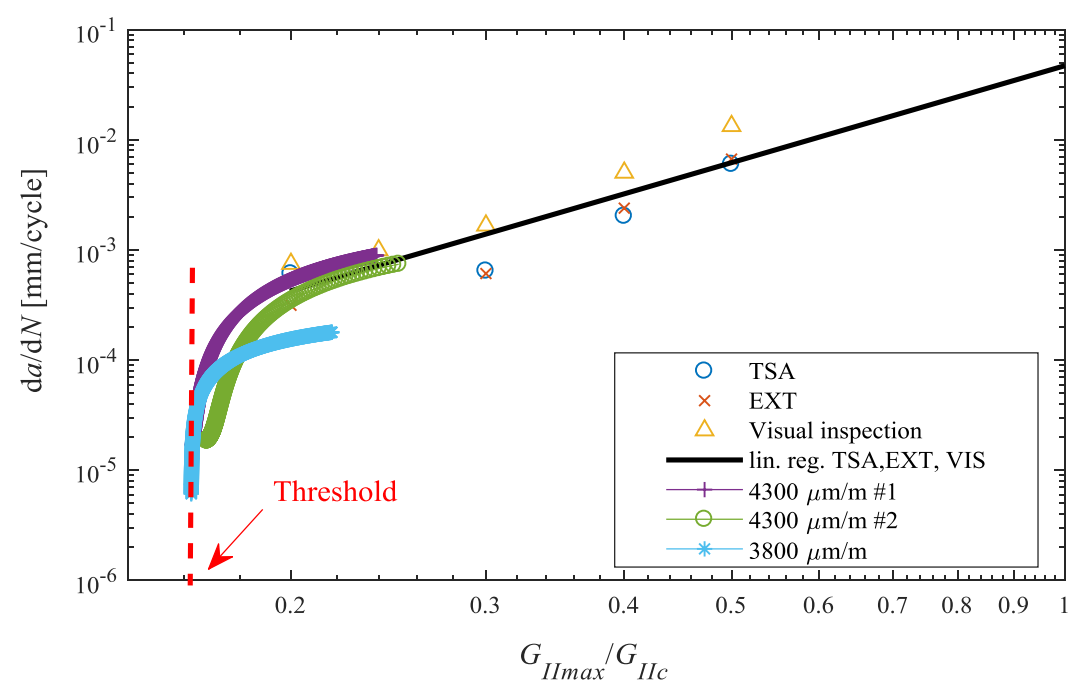

Figure 7: Paris curves from the load and strain control experiments. 


\section{Conclusions}

The Transverse Cut Tensile sample in its modified form, MTCT, was tested under load, displacement and strain control, in order to characterize the fatigue Mode II fracture toughness of FRP materials. For the first time, the MTCT specimen was tested in strain control mode. The present paper illustrates the advantages of a displacement/strain control driven fatigue test, evidencing how such loading strategy, coupled with the use of extensometers able to monitor the compliance variation, may lead to a semi-analytical representation of the material crack growth curve in the onset or threshold region. The proposed methodology is able to characterize a whole part of the crack growth curve, including the subcritical crack onset region and the subsequent linear growth region (Paris'law), in a rapid and effective way, by just using only one sample, and only one experiment, which may extend up to only a few hundred of thousand cycles. The adoption of one sample and the continuous compliance monitoring allow for obtaining a smooth and low scattered curve that can ideally be used to improve fitting of total fatigue-life models (see e.g. [11]).

Experimental results confirmed that testing an MTCT sample under displacement (or strain) control, leads to a delamination growth with a negative crack growth speed rate, with a natural growth arrest after a relatively short number of fatigue cycles. This approach allows to evaluate, in an effective and reliable way, the threshold fracture toughness $G_{I I t h}$ of the material. Evidence of the validity of the analytical expressions linking the crack growth rate to the applied load and to the extensometer deformation, and a demonstration on how such analytical models may provide a representation of the threshold region of the Paris' curve, were provided.

Finally, it should be noted how the proposed methodology will particularly be useful to designers following a "no growth" approach to structural design, and therefore is well suited and compatible with current industrial material testing and qualification protocols.

\section{Acknowledgments}

Part of the experimental activity has been carried out by using the IR thermal camera FLIR X6540sc, which has been purchased using funds from the project INTEP - PO FESR 2007/2013 - 4.1.2.A. 


\section{References}

[1] de Vries TJ, Vlot A, Hashagen F. Delamination behavior of spliced Fiber Metal Laminates. Part 1. Experimental results. Compos Struct 1999;46:131-45. doi:https://doi.org/10.1016/S0263-8223(99)00049-5.

[2] Prieto L, Spenninger G, Wagner H. Experimental Determination of Energy Release Rate of Cfrp Structures by Means of Transverse Crack Tension Tests. In: Bos M, editor. ICAF 2009, Bridg. Gap between Theory Oper. Pract., Springer, Dordrecht; 2009, p. 513-28.

[3] Suiker ASJ, Fleck NA. Crack tunneling and plane-strain delamination in layered solids. Int J Fract 2004;125:1-32. doi:10.1023/B:FRAC.0000021064.52949.e2.

[4] Catalanotti G, Furtado C, Scalici T, Pitarresi G, van der Meer FP, Camanho PP. The effect of through-thickness compressive stress on mode II interlaminar fracture toughness. Compos Struct 2017;182:153-63. doi:10.1016/j.compstruct.2017.09.014.

[5] Bak BL V., Sarrado C, Turon A, Costa J. Delamination Under Fatigue Loads in Composite Laminates: A Review on the Observed Phenomenology and Computational Methods. Appl Mech Rev 2014;66:060803. doi:10.1115/1.4027647.

[6] Brunner AJ, Stelzer S, Pinter G, Terrasi GP. Cyclic fatigue delamination of carbon fiberreinforced polymer-matrix composites: Data analysis and design considerations. Int J Fatigue 2016;83:293-9. doi:10.1016/j.ijfatigue.2015.10.025.

[7] Carreras L, Renart J, Turon A, Costa J, Essa Y, Martin de la Escalera F. An efficient methodology for the experimental characterization of mode II delamination growth under fatigue loading. Int J Fatigue 2017;95:185-93. doi:10.1016/j.ijfatigue.2016.10.017.

[8] Brunner AJ. Scatter, Scope and Structures: What fatigue fracture testing of fiber polymer composites is all about. IOP Conf Ser Mater Sci Eng 2018;388:1-18. doi:10.1088/1757- 
899X/388/1/012003.

[9] Asp L, Sjögren A, Greenhalgh E. Delamination Growth and Thresholds in a Carbon/Epoxy Composite Under Fatigue Loading. J Compos Technol Res 2010;23:55. doi:10.1520/ctr10914j.

[10] O’Brien TK, Johnston WM, Toland GJ. Mode II interlaminar fracture toughness and fatigue characterization of a graphite epoxy composite material. NASA Tech Rep NASA/TM-2010216838 2010:1-32.

[11]Panduranga R, Shivakumar K. Mode-II total fatigue life model for unidirectional IM7/8552 carbon/epoxy composite laminate. Int J Fatigue 2017;94:97-109. doi:10.1016/j.ijfatigue.2016.09.014.

[12] Murri GB. Evaluation of delamination onset and growth characterization methods under mode I fatigue loading. NASA Tech Rep NASA/TM-2013-217966 2013:1-27.

[13] Shivakumar K, Chen H, Abali F, Le D, Davis C. A total fatigue life model for mode i delaminated composite laminates. Int J Fatigue 2006;28:33-42. doi:10.1016/j.ijfatigue.2005.04.006.

[14]Chen H, Shivakumar K, Abali F. A comparison of total fatigue life models for composite laminates. Fatigue Fract Eng Mater Struct 2006;29:31-9. doi:10.1111/j.14602695.2006.00958.x.

[15]ASTM D6115 - Standard test method for mode I fatigue delamination growth onset of unidirectional fiber-reinforced polymer matrix composites, vol. 15.03, Annual Book of ASTM Standards, ASTM International, West Conshohocken, PA. 2003.

[16]Wilk J. Compliance based method for testing fatigue delamination propagation in laminates. Eng Fract Mech 2018;203:137-51. doi:10.1016/j.engfracmech.2018.06.043. 
[17] Scalici T, Pitarresi G, Catalanotti G, van der Meer FP, Valenza A. The Transverse Crack Tension test revisited: An experimental and numerical study. Compos Struct 2016;158:144-59. doi:10.1016/j.compstruct.2016.09.033.

[18]Prinz R, Gädke M, Gadke M. Characterization of interlaminar mode I and mode II fracture in CFRP laminates. Proc. Inter. Conf. Spacecr. Struct. Mech. Testing. ESA SP-321, 1991, p. 97102.

[19]Wisnom MRMR. On the Increase in Fracture Energy with Thickness in Delamination of Unidirectional Glass Fibre-Epoxy with Cut Central Plies. J Reinf Plast Compos 1992;11:897909. doi:10.1177/073168449201100802.

[20]Cui W, Wisnom MR, Jones M. An Experimental and Analytical Study of Delamination of Unidirectional Specimens with Cut Central Plies. J Reinf Plast Compos 1994;13:722-39. doi:10.1177/073168449401300804.

[21]Pitarresi G, Scalici T, Catalanotti G. Infrared Thermography assisted evaluation of static and fatigue Mode II fracture toughness in FRP composites. Compos Struct 2019;226:111220. doi:https://doi.org/10.1016/j.compstruct.2019.111220.

[22] König M, Krüger R, Kussmaul K, Von Alberti M, Gädke M. Characterizing static and fatigue interlaminar fracture behavior of a first generation graphite/epoxy composite. ASTM Spec Tech Publ 1997;1242:60-81. doi:10.1520/STP18270S.

[23] Allegri G, Jones MI, Wisnom MR, Hallett SR. A new semi-empirical model for stress ratio effect on mode II fatigue delamination growth. Compos Part A Appl Sci Manuf 2011;42:73340. doi:10.1016/j.compositesa.2011.02.013.

[24] Scalici T, Pitarresi G, Badagliacco D, Fiore V, Valenza A. Mechanical properties of basalt fiber reinforced composites manufactured with different vacuum assisted impregnation techniques. 
Compos Part B Eng 2016. doi:10.1016/j.compositesb.2016.08.021.

[25]Bergmann HW, Prinz R. Fatigue life estimation of graphite/epoxy laminates under consideration of delamination growth. Int J Numer Methods Eng 1989;27:323-41. doi:10.1002/nme.1620270208.

[26] Kawashita LF, Jones MI, Trask RS, Hallett SR, Wisnom MR. Static and fatigue delamination from discontinuous plies - Experimental and numerical investigations. ICCM Int. Conf. Compos. Mater., 2009.

[27] Wang W, Rans C, Benedictus R. Theoretical analysis of fatigue failure in mechanically fastened Fibre Metal Laminate joints containing multiple cracks. Eng Fail Anal 2018;91:15164. doi:10.1016/j.engfailanal.2018.03.012.

[28]Rans CD, Atkinson J, Li C. On the onset of the asymptotic stable fracture region in the mode II fatigue delamination growth behaviour of composites. J Compos Mater 2014;49:685-97. doi:10.1177/0021998314525482.

[29]Ribeiro F, Martinez M, Rans C. Evaluation of Mode Ii Fatigue Durability of Bonded Composite Repairs Using the Central Cut Plies. Meet Aeronaut Compos Mater Struct MACMS 2015 2015:1-9.

[30]Pitarresi G. Lock-In Signal Post-Processing Techniques in Infra-Red Thermography for Materials Structural Evaluation. Exp Mech 2015;55:667-80. doi:10.1007/s11340-013-9827-1.

[31] Murri GB, Martin RH. Effect of initial delamination on mode 1 and mode ii interlaminar fracture fracture toughness threshold. NASA Tech Memo AVSCOM TR-91-B-005 1991. 


\section{Figure Captions}

Figure 1: Sketch of a MTCT specimen.

Figure 2: (a) Sketch of an MTCT sample instrumented with the extensometer; (b) image of the HBM dd1 strain indicator assembled in an averaging double opposed clamp on configuration.

Figure 3: Plots of the Load-Displacement curves measured from monotonic tests up to failure on MTCT samples.

Figure 4: Paris law evaluation of the fatigue loading behaviour under load control.

Figure 5: Example of average delamination growth as predicted with the EXT method.

Figure 6: (a) Evolution of the load at maximum displacement during a fatigue test in displacement control; (b) evolution of the load at maximum strain in fatigue tests run in strain control.

Figure 7: Paris curves from the load and strain control experiments.

\section{Table Caption}

Table 1: Plan of experiments: test type and test parameters adopted for each MTCT sample.

Table 2: Fatigue tests under load control with $\mathrm{R}=0.1$ and load frequency $5 \mathrm{~Hz}$.

Table 3: Fatigue tests under strain control with $\mathrm{R}=0.1$ and load frequency $5 \mathrm{~Hz}$. 